Article

\title{
Does the Impact of Carbon Price Determinants Change with the Different Quantiles of Carbon Prices? Evidence from China ETS Pilots
}

\author{
Wenjun Chu ${ }^{1}$, Shanglei Chai ${ }^{1} * * \mathbb{D}, \mathrm{Xi}_{\mathrm{C}} \mathrm{Chen}^{2}$ and $\mathrm{Mo} \mathrm{Du}^{3}$ \\ 1 School of Business, Shandong Normal University, Jinan 250014, China; 201724010218@stu.sdnu.edu.cn \\ 2 Department of Management Engineering, School of Economics \& Management, Xidian University, \\ Xi'an 710071, China; xchen@xidian.edu.cn \\ 3 School of Accounting, Shandong Youth University of Political Science, 31699 East Jingshi Road, \\ Licheng District, Jinan 250103, China; 110051@sdyu.edu.cn \\ * Correspondence: chaishanglei@sdnu.edu.cn
}

Received: 18 June 2020; Accepted: 8 July 2020; Published: 10 July 2020

check for updates

\begin{abstract}
Since carbon price volatility is critical to the risk management of the $\mathrm{CO}_{2}$ emissions trading market, research has focused on energy prices and macroeconomic drivers which cause changes in carbon prices and make the carbon market more volatile than other markets. However, they have ignored whether the impact of carbon price determinants changes when the carbon price is at different levels. To fill this gap, this paper applies a semiparametric quantile regression model to explore the effects of energy prices and macroeconomic drivers on carbon prices at different quantiles. The model combines the advantages of parameter estimation, nonparametric estimation and quantile regression to describe the nonlinear relationship between carbon price and its fundamentals, which do not need to make any assumptions about the random error. Carbon prices are high-tailed and exhibit higher kurtosis, the traditional models which tend to assume that data are normally distributed can't perform well. Furthermore, the semiparametric model doesn't need to assume that the data are normally distributed. Therefore, the semiparametric model can effectively model the data. Some new evidence from China's emission trading scheme (ETS) pilots shows that energy prices and macroeconomic drivers have different effects on carbon prices at high or low quantiles. First, the negative impact of coal prices on carbon prices was greater at the lower quantile of carbon prices in the Shenzhen ETS pilot. However, the effects of coal prices were positive in the Beijing ETS pilot, which may be attributed to great demand for coal. Second, oil prices had greater negative effects on carbon prices at higher quantiles in Beijing and Hubei ETS pilots. This can be attributed to the fact that businesses use less oil when carbon prices are high. For the Shenzhen ETS pilot, the effects of oil prices were positive. Third, natural gas prices have a stronger effect on carbon prices as quantiles increased in the Beijing and Hubei ETS pilots. Lastly, the effects of macroeconomic drivers on carbon prices at low quantiles were stronger in the Shenzhen ETS pilots and higher at the medium quantiles in Beijing and Hubei ETS pilots. These findings suggest that the impact of determinants on the carbon prices at different levels is not constant. Ignoring this issue will lead to a missed warning about the risks of the carbon market. This study will be of positive significance for China's emission trading scheme (ETS) pilots, in order to accurately monitor the effects of carbon prices determinants and effectively avoid carbon market risks.
\end{abstract}

Keywords: semiparametric quantile regression; China's ETS pilot; carbon price; energy price; macroeconomic level 


\section{Introduction}

Global climate change endangers ecological security, and has become the largest threat to the world's sustainable development. In response to the 2030 Sustainable Development Goals (SDGs) proposed by the United Nations, China has launched emission trading scheme (ETS) pilots and a national carbon market to reduce carbon emissions and achieve sustainable development. As the intensity of carbon emissions trading increases, carbon price fluctuations will affect the confidence of market participants. For risk management applications, it is necessary to know the price determinants of $\mathrm{CO}_{2}$ emission certificates. In this context, there are a couple of issues worthy of attention, i.e., (1) what exactly influences the carbon price and how does it affect it? (2) is this effect constant or variable with the different levels of carbon prices? In this paper, we elaborate on these questions in more detail.

Due to the rapid development of the global economy and the acceleration of industrialization, fossil fuels have been extensively used in recent decades, resulting in a large amount of $\mathrm{CO}_{2}$ emissions. According to Dudley [1], carbon emissions from energy consumption increased by $2 \%$ in 2018, reaching their highest level since 2011. These emissions have greatly affected the sustainable development of human society; therefore, they are concern worldwide. To address the environmental challenges caused by climate change, the well-known 2030 Agenda and Paris Agreement have been adopted to coherently implement climate action and sustainable development practices [2]. The 2030 Agenda for Sustainable Development has been advanced for coordination between global economic development and environmental protection [3]. However, the Paris Agreement aims at strengthening the global response to climate change by controlling the temperature goal [4].

To comply these agreements, China has been actively participating in an international cooperation to achieve peak carbon emissions by approximately 2030 using carbon emission trading pilots and a nationwide carbon market [5], which is considered a cost-effective method market mechanism in climate change mitigation [6-8]. To develop a carbon emission trading market, China has launched several pilots in Beijing, Hubei, Shenzhen, Guangdong, Shanghai, Tianjin and Chongqing since 2013, and a pilot in Fujian in 2016, while a national carbon market was started on 19 December 2017 [9]. All these attempts are rather novel in China, which is far from having a mature carbon emission trading scheme. Several lines of evidence have shown that many limitations exist in the pilot ETSs operating in China, such as their immature financial support, weak market liquidity and uncertain information transmission, etc. [10-12]. These factors result in price abnormalities, which may adversely influence the development of the carbon market in China [13]. To overcome these limitations, it is essential to understand carbon prices dynamics and to establish a scientific influencing mechanism between the price of carbon and its determinants. This study may not only help policy-makers formulate a reasonable carbon pricing mechanism but also provide useful information for businesses and investors who participate in carbon trading activities, in order to help them manage the risk caused by carbon price fluctuations.

Many scholars have studied the determinants on carbon prices, which are mainly divided into two categories. One category of literature focuses on the effects of energy prices on carbon prices [14-26]. Hammoudeh et al. [18] analyzed the effects of coal prices, oil prices and natural gas prices on carbon prices, and found that an increase in natural gas prices can restrain carbon prices, but coal prices had no significant effects on carbon prices. Yu et al. [21] comprehensively considered the linear and nonlinear relationships between the carbon market and the crude oil market. Employing linear and nonlinear Granger tests and multiscale analyses, these authors found that there are different causal relationships between carbon prices and oil prices at different time scales. Hammoudeh et al. [20] used a nonlinear autoregressive distributed lag model to analyze the nonlinear effects of energy prices on carbon prices, and found that oil prices and natural gas prices negatively affect carbon prices. Zhang and Sun [22] found a positive relationship between the carbon market and the energy market. Chevallier et al. [25] found a negative correlation between carbon prices and natural gas prices in the EU ETS. 
Another category of literature focuses on the effects of the macroeconomic level on carbon prices. Instead of arriving at a consistent conclusion, the existing literature can be summarized into different viewpoints on the positive or negative effects. Several scholars have suggested a positive relationship between macroeconomic factors and carbon prices [27-32]. Koch et al. [29] employed multivariate regression models to research the effects of macroeconomic activities in Phase II and the first year of Phase III; they found that macroeconomic activities positively impacted European Union Allowances (EUA) prices. Jiménez-Rodríguez [31] tested for causality between the main European stock market indices and prices in three phases of the EU ETS, and concluded that economic activities positively impact EUA prices, except for those in Phase I. However, several scholars have argued that the macroeconomic level has a negative influence on carbon prices $[16,33,34]$, which is contrary to the positive relationship between macroeconomic factors and carbon prices confirmed by most studies. Several studies have confirmed a nonlinear relationship between the macroeconomy and carbon prices $[24,27,28]$. Yuan and Yang [32] employed a generalized autoregressive score-dynamic conditional score-Copula (GAS-DCS-Copula), and found that stock market uncertainty can transfer risk to carbon market.

To explain this disagreement, Cai et al. [35] proposed that the contradictory empirical results may be caused by nonlinearities in the objects studied. As Zhu et al. [24] point out, most existing studies have only focused on the linear relationship between carbon prices and their determinants by adopting linear models, but have ignored the nonlinear relationships that may be contained among them. Ignoring these nonlinearities may be insufficient for the full examination of the effects of factors on carbon prices. A quantile regression can effectively examine the nonlinear effects of energy prices [19] and the macroeconomic level on carbon prices. Unlike energy prices, the macroeconomic level can indirectly affect carbon prices. There is an inseparable relationship between the macroeconomic level and industrial production [34], which causes carbon emissions. Carbon emissions can affect carbon prices via the demand for carbon allowances. The nonparametric analysis has been used to analyze the relationship between economic development and carbon emissions [36,37]. Accordingly, we also employed nonparametric analysis to investigate the impacts of the macroeconomic level on carbon prices.

Therefore, we propose a semiparametric quantile regression model that combines the advantages of parameters estimation, nonparametric estimation and quantile regression to describe the nonlinear relationship between carbon price and its fundamentals. This method shows greater flexibility than the specified parametric model [38]. We set a function as the nonparametric part of the model to reflect the effects of the macroeconomic factors on carbon prices and allow the effects of energy prices (coal, oil and natural gas) to be parametric in form. The approach of quantile regression first introduced by Koenker and Basset [39] aimed to investigate the effects of an observable covariate on conditional quantiles of the distribution of the response, instead of solely the effect of the covariate on the conditional mean [40]. Since this study, quantile regression has become a popular method because of its improved statistical properties in empirical studies of financial issues [41-44]. Lee and Li [42] examined the effects of diversification on firm performance based on quantile regression. Zhu et al. [43] employed a panel quantile regression to investigate the dependence between real crude oil and Chinese real stock market returns. Jiang et al. [44] used a quantile regression to investigate the effects of capital buffer on bank risk-taking in China.

Many researches have focuses on the dynamics of carbon prices in EU ETS; however, the construction of China's carbon market cannot completely replicate the EU's mature experience, as China has very different policy planning, and a very different economic system and market maturity relative to those of the EU [45-47]. Therefore, it is necessary to study the factors that influence the carbon market in accordance with China's national conditions; related research is rather sparse [13,48-50]. This literature gap restricts our understanding of the mechanisms that impact China's carbon prices, and hinders the formulation of regulators' carbon pricing policies and the management of investors' risk related to carbon price volatility [51]. Therefore, we employed semiparametric quantile regression to examine the effects of energy prices and the macroeconomic level on carbon prices in China to 
analyze the effects of determinants on carbon prices for different carbon prices, which is of great practical significance. In this paper, we capture the effects of the macroeconomic level on carbon prices through the nonparametric component of semiparametric quantile regression.

The main contributions of this paper are threefold. First, we introduce a semiparametric quantile model to investigate the mechanism that influences the relationship between carbon prices and their determinants, which is more flexible and robust than the methods that have been used in the existing literature. Second, this paper addresses concerns about the context of China's carbon emissions trading pilots in Beijing, Hubei and Shenzhen, which lack research but urgently need to be studied. Third, we draw several new and valuable conclusions, which are different from those in previous literature. The remainder of this paper is organized as follows. Section 2 details the methodology of semiparametric quantile regression and the data we used. Section 3 displays the results. Section 4 describes the conclusions and policy implications.

\section{Methodology and Data}

\subsection{Methodology}

Compared with ordinary least square, the quantile regression model is more robust, mainly because the quantile regression model does not need to make any assumptions about the random error, so the random error term in the model can satisfy any probability analysis. What's more, the quantile regression model has strong resistance to outliers in data because quantile regression is a regression analysis of all quantiles. Unlike the ordinary least square, which only fits a curve, quantile regression can fit a cluster curve. When independent variables have different effects on the distribution of dependent variables in different parts, the general characteristics of conditional distribution can be described more comprehensively. The traditional models tend to assume that data are normally distributed, while the evidence shows that carbon prices are heavy-tailed, and exhibit higher kurtosis and heteroscedasticity $[8,12,52-54]$. Without any assumptions of the data distribution, the proposed semiparametric quantile regression model is robust and can fully describe the distribution of the dependent variable to reflect the tail characteristics of the distribution. Additionally, previous studies that focused on the effects of determinants on carbon prices failed to assess the effects on the extreme distribution of carbon prices, resulting in an incomplete analysis. The semiparametric quantile regression can fully capture the effects of the determinants on carbon prices under both normal and extreme conditions.

To assess the possibility of a nonlinear relationship between carbon price and its fundamentals, we employ a semiparametric quantile regression model for this issue, which was developed by Koenker [55]. The biggest advantage of this model is that it can not only observe the complex relationship between variables but also capture differences in effects across quantile levels, so that the model has a wide application space. The semiparametric quantile regression conditional function of $y_{i}$, given $x_{i}$ in $\theta$-th quantile, can be expressed as:

$$
Q_{y_{i}}(\theta \mid x)=x_{i}^{\prime} \beta(\theta)+\sum_{d=1}^{D} m_{d, \theta}\left(x_{i d}\right)
$$

where $y$ is the dependent variable which is assumed to rely on $x$. As for $\beta(\theta)$, where $\theta \epsilon[0,1]$, it represents the unknown parameter vector of the semiparametric quantile regression. Furthermore, $m_{d}\left(x_{i d}\right)$, a nonparametric component whose form is arbitrary, is utilized to make local adjustment to the explanatory variable. In our study, we choose energy prices as parametric components and the macroeconomic level as the nonparametric component.

We can estimate $\beta(\theta)$ by solving for the following minimization problem:

$$
\begin{aligned}
& \hat{\beta}(\theta)=\arg _{(\beta(\theta), m)}^{\min } \sum \rho_{\theta}\left(y_{i}-x_{i}^{\prime} \beta(\theta)-\sum_{d=1}^{D} m_{d, \theta}\left(x_{i d}\right)\right)+\lambda_{0}\|\beta(\theta)\|_{1}+ \\
& \sum_{d=1}^{D} \lambda_{d} \vee\left(\nabla m_{d, \theta}\right)
\end{aligned}
$$


where the loss function $\rho_{\theta}(\mu)$ is defined as:

$$
\rho_{\theta}(\mu)=\mu(\theta-I(\mu<0))
$$

and $I($.$) is the indicator function. The method divides the residuals into positive and negative values,$ and the weights are $\theta$ and $1-\theta[39] .\|\beta(\theta)\|_{1}=\sum_{k=1}^{K}\left|\beta(\theta)_{k}\right|$, and $\left(\nabla m_{d}\right)$ represents the total variation of the derivative of $m$ (or the gradient vector), and are defined precisely in Koenker [55]. According to Koenker [55], the selection of $\lambda$ relies on a Schwarz [56] like criterion,

$$
\operatorname{SIC}(\lambda)=n \log \hat{\sigma}(\lambda)+\frac{1}{2} p(\lambda) \log (n)
$$

where $\hat{\sigma}(\lambda)=n^{-1} \sum_{i=1}^{n} \rho_{\theta}\left(y_{i}-x_{i}^{\prime} \beta(\theta)-\sum_{d=1}^{D} m_{d, \theta}\left(x_{i d}\right)\right), p(\lambda)$ is the effective dimension of the fitted model. Koenker [55] proposed to narrow the region of optimization and then resort to some form of global optimizer to narrow the selection. We can optimize SIC $(\lambda)$ through the $\mathbf{R}$ function. The $\mathbf{R}$ codes used to construct model are provided in Koenker [55].

In order to reduce the fluctuations and heteroscedasticity of the time series, we measured the data in natural logarithms. $y_{i}$ is the dependent variable which denotes the log of carbon prices, including BJA, HBA and SZA. $i$ represents the time frame from the launch date of each pilot to 28th June 2019. The coal, oil and natural gas price for time point $i$ are denoted by $C O A L_{i}, O I L_{i}$ and $L N G_{i}$, respectively. $S T O C K_{i}$ for time point $i$ denotes the daily closing prices of the Shanghai composite index, which is the proxy of the macroeconomic level according to the existing literature $[24,34,51,57]$. $\beta_{1}(\theta), \beta_{2}(\theta)$ and $\beta_{3}(\theta)$ show the marginal effects of coal prices, oil prices and natural gas prices on the $\theta$ quantiles,

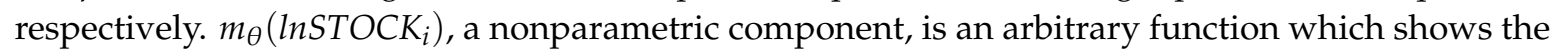
nonlinear effect of the macroeconomic level on the carbon price on the $\theta$ quantiles. $\ln C O A L_{i}, \ln O L_{i}$, $\ln L N G_{i}, \operatorname{lnSTOCK_{i}}$ represent the natural logarithm of coal prices, oil prices, natural gas prices and the closing price of the Shanghai composite index. For the specific issue we study, the semiparametric quantile regression is given by

$$
Q_{y_{i}}\left(\theta \mid x_{i}\right)=\alpha(\theta)+\beta_{1}(\theta) \ln C O A L_{i}+\beta_{2}(\theta) \ln O I L_{i}+\beta_{3}(\theta) \ln L N G_{i}+m_{\theta}\left(\ln S T O C K_{i}\right)
$$

where $\alpha(\theta)$ denotes the intercept on the $\theta$ quantiles. Generally, this model can capture the marginal effects of energy prices on carbon prices by parametric components, and the effects of macroeconomic level on carbon prices can be expressed by the nonparametric component.

\subsection{Data}

This paper examines the dependence between the carbon price and its determinants in China's ETS pilots. Until the end of June 2019, all the ETS pilots considered here covered approximately 3000 key emission units in power, steel, cement and other industries. The accumulated trading volume exceeded 330 million tons, for a total value of approximately CNY 7.1 billion. The total amount and intensity of carbon emissions in the pilot areas achieved a 'double decline', which confirms that the carbon market has been effective for controlling carbon emissions.

In this study, we selected three ETS pilots (Beijing, Hubei and Shenzhen) in which to conduct empirical analyses, and we considered the representative and particular features of these ETS pilots as follows. First, China's carbon pilots span the northern, central and western, and southeast coastal regions, including a total GDP of 22 trillion yuan and an energy consumption of 840 million tons of standard coal, which account for $19 \%, 30 \%$ and $21 \%$ of the total amount, respectively [58]. Among the pilots, Beijing, Hubei and Shenzhen are exactly representative of northern China, central and western China, and the southeast coastal areas, respectively. The three pilots have both common features and regional differences, which are highly representative.

Second, these three ETS pilots have their own characteristics. Beijing is the capital of China, and its level of economic development has always been at the forefront of Chinese cities. The recent structure 
and growth rate of carbon emissions in Beijing are significantly different from those of other pilot provinces and cities. The design of the pilot system fully takes into account the phased characteristics of social and economic development, energy consumption and carbon emissions [59]. The Hubei ETS pilot had been in full operation for two cycles by 2017; it led the trade volume and had good market liquidity and basically stable carbon prices without a sharp rise or fall, as shown in Figure 1. The accumulated trading volume was 37.386 million tons, accounting for $37 \%$ of the national total. The system design of the Hubei ETS pilot played an important role in ensuring the stable operation of the carbon market, and coordinating economic development and emission reduction. In contrast to the Beijing and Hubei ETS pilots, the Shenzhen ETS pilot was the only pilot at the sub-province level, but it was the first of the pilots in China to start operating. The Shenzhen ETS pilot covered a total of 794 entities from a broad scope across the energy, industry, building and transport sectors [60].
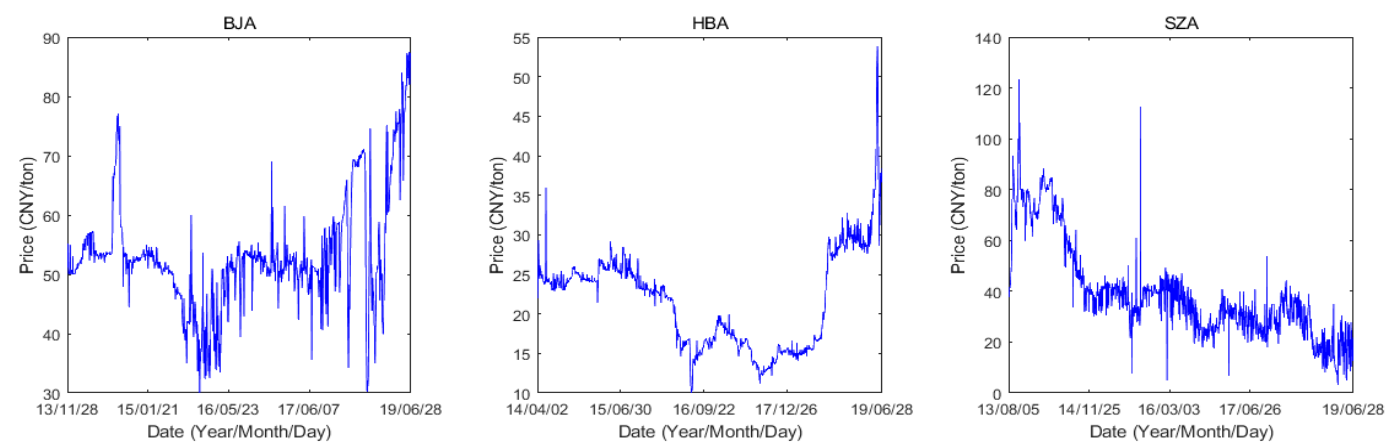

Figure 1. Dynamics of carbon prices in the Beijing, Hubei and Shenzhen ETS pilots.

The daily closing carbon prices of the Beijing allowances (BJA), the Hubei allowances (HBA) and the Shenzhen allowances (SZA) range from the launch date of each pilot to 28th June 2019, and were collected from the CSMAR database (http://www.gtarsc.com/). It is worthwhile to note that the SZA prices are offered by the SZA-2013, SZA-2014, SZA-2015, SZA-2016, SZA-2017, SZA-2018 and SZA-2019 products, respectively, which is because of the actual operation of the market. When the Shenzhen ETS pilot was launched in June 2013, there were only 2013 Shenzhen allowances (SZA-2013) for tradable products on the market. During subsequent operation, the allowances issued in each year were used to fulfill that year and subsequent years. After seven years of market operation, the currently tradable allowances include SZA-2013, SZA-2014, SZA-2015, SZA-2016, SZA-2017, SZA-2018 and SZA-2019 [60]. For consistency of calculation, the prices of average emissions allowances of all trading products were computed from sample data following Chang et al. [61].

The dynamic characteristics of the prices of carbon emission allowances among the three ETS pilots are graphically displayed in Figure 1. In terms of the long-term trend in carbon price fluctuations, trading in Beijing and Hubei ETS pilots have generally exhibited a 'rushing down after up and rushing high again' state in recent years, while the Shenzhen ETS pilot has generally entered a 'continuous decline with small increase' state in the long run. Figure 1 shows that the average trading price in each market was 20 55 CNY/ton in the initial stage of the carbon pilots. Among these, the trading price in the Hubei ETS pilot was the lowest, at just over $20 \mathrm{CNY/ton.} \mathrm{Although} \mathrm{prices} \mathrm{in} \mathrm{the} \mathrm{Beijing}$ and Shenzhen ETS pilots started out high, they fell sharply over the next few years. Especially in 2015, when the first fulfilling term came, all pilots showed a 'high opening and low closing' trend in public trading prices. After fulfillment, the trading prices of all of the pilots gradually picked up and became relatively stable. At the end of 2015, Beijing and Shenzhen kept floating at the high price of $40 \mathrm{CNY} /$ ton, which was ahead of other pilots. The price of the Hubei ETS pilot hovered at approximately $22 \mathrm{CNY} /$ ton, which was relatively low, but moderate. In 2016, only the price of the Beijing ETS pilot remained stable, above $50 \mathrm{CNY} /$ ton with an upward trend, while prices in the other pilots continued to fall [62]. After the first fulfillment term of the Shenzhen ETS pilot, the price dropped to below $25 \mathrm{CNY} /$ ton. At the end of December 2016, the price in the Hubei ETS pilot fell at the 
beginning and then rose, stabilizing at around $19 \mathrm{CNY} /$ ton at the end of the year. From the middle of 2018, the allowance price in Hubei rose from $16 \mathrm{CNY/ton}$ to $30 \mathrm{CNY} /$ ton [60], while prices fluctuated wildly in Beijing and declined in Shenzhen.

The amplitudes of the carbon price fluctuations in the Beijing and Shenzhen ETS pilots were more volatile than those in Hubei. In the latest year, the trading price in the Beijing ETS pilot fluctuated greatly, with a sharp decline of $30 \mathrm{CNY}$ /ton in September 2018, and a rapid increase to $61 \mathrm{CNY/ton}$ in October 2018, finally reaching the peak of 87 CNY/ton in June 2019. Unlike Beijing's relatively large fluctuations, the Shenzhen ETS pilot showed more short-term fluctuations, in which the price jumped from $40 \mathrm{CNY}$ /ton to $122 \mathrm{CNY}$ /ton in the early launching stage, and then gradually decreased until it became relatively stable within the price range of 20-40 CNY/ton. Contrary to these results, the Hubei ETS pilot's price volatility was relatively modest. The volatility in the price brings great risks to the stability of the carbon market, which is not conducive to the participation of stakeholders in the market. From the evidence seen in Figure 1, we can conclude that it is significant for China to explore the factors that impact the carbon price and cause it to change.

In term of the factors that impact carbon prices, this paper focuses on macroeconomic factors and energy prices, including coal, oil and natural gas prices. The coal price, represented by the thermal coal exit price in Tianjin port, was obtained from the Wind database (denoted by COAL). Oil prices are represented by the settlement price of fuel oil futures, and were obtained from the Wind database (denoted by OIL). In addition, natural gas prices obtained from the Wind database were collected from the average ex-factory price of the liquid natural gas from the six quotation agencies (denoted by LNG). In addition to energy prices, macroeconomic factors also drive carbon prices due to the impact of the productive activities of enterprises, which lead to carbon emissions. Thus, the macroeconomic level is the key determinant of carbon prices. In this study, we took the closing prices of the Shanghai composite index as the proxy of macroeconomic level $[24,34,51,57]$ from Yahoo Finance (https://finance.yahoo.com/), denoted by STOCK. The dynamics of coal prices, oil prices, natural gas prices and the closing price of the Shanghai composite index are exhibited in Figure 2. Figure 2 shows the data series of the driving factors, from which we observe a market crash between 2015 and 2016. The SSE composite index reached a maximum in June 2015, but then decreased sharply. Coal prices were at their lowest in December 2015, and the price then increased dramatically and became relatively stable. From August 2013 to January 2016, the oil prices dropped from $5000 \mathrm{CNY/ton}$ to $2000 \mathrm{CNY/ton}$ gradually. The price stayed relatively stable between 2016 and 2017. COAL and OIL rose rapidly between August 2016 and February 2017, and the prices remained high. The LNG fluctuated violently between 2017 and 2018. The natural gas prices fluctuated more dramatically than coal prices and oil prices. From Figure 2, natural gas prices were higher than the other two kinds of energy.
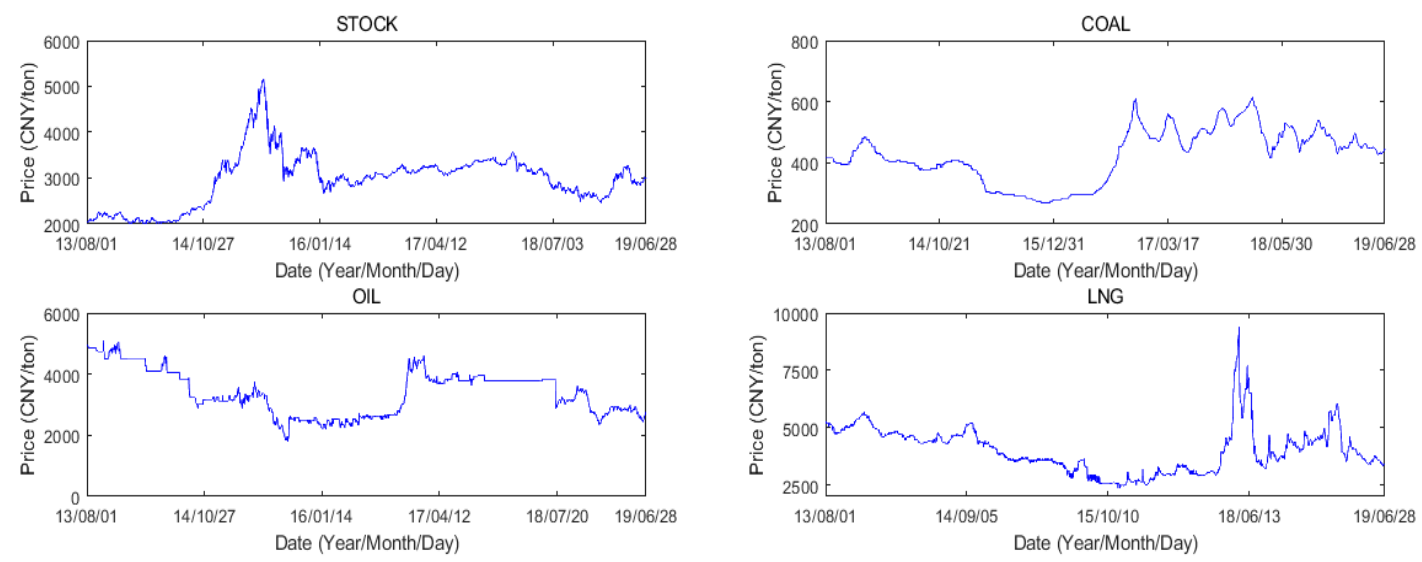

Figure 2. Dynamics of SSE composite index closing prices and energy prices. 


\section{Results}

\subsection{Descriptive Statistics, Normality Test and Nonlinear Test}

Descriptive statistics of the carbon prices in the three ETS pilots, energy prices and the Shanghai composite index are summarized in Table 1.

Table 1. Descriptive statistical results of carbon price and the price of its fundamentals.

\begin{tabular}{cccccccc}
\hline & BJA & HBA & SZA & LNG & COAL & OIL & STOCK \\
\hline Mean & 53.292 & 21.622 & 39.137 & 4012.672 & 424.229 & 3390.796 & 2958.016 \\
Median & 52.110 & 23.000 & 34.920 & 3887.500 & 433.000 & 3315.000 & 3051.724 \\
Maximum & 87.470 & 53.850 & 122.970 & 9400.000 & 613.000 & 5075.000 & 5166.350 \\
Minimum & 30.000 & 10.070 & 3.300 & 2380.000 & 270.000 & 1832.000 & 1991.253 \\
Std.Dev & 9.730 & 6.119 & 19.065 & 1000.010 & 88.084 & 732.739 & 577.937 \\
Skewness & 0.952 & 0.703 & 1.145 & 0.972 & -0.159 & 0.181 & 0.474 \\
Kurtosis & 4.746 & 4.428 & 4.055 & 5.260 & 2.119 & 2.040 & 4.071 \\
Jarque-Bera & 236.889 & 207.963 & 340.484 & 733.466 & 53.688 & 62.582 & 122.609 \\
Probability & 0.000 & 0.000 & 0.000 & 0.000 & 0.000 & 0.000 & 0.000 \\
\hline
\end{tabular}

The Jarque-Bera tests for each ETS pilot reject the null hypothesis that the skewness is zero and the kurtosis is three. Therefore, the results of the Jarque-Bera tests demonstrate that all of the variables have non-normal distributions. In addition, we applied ordinary least square regression (OLS) to model the relationship between the carbon prices in each ETS pilot and coal prices, oil prices, natural gas prices and the macroeconomic level. The data is measured in natural logarithms. The kernel density estimation, the frequency histogram and the normally distributed density function graph of the residuals are shown together for comparison in Figure 3, which reflects the normality of the data. It shows that each residual is non-normal; therefore, OLS is not suitable for modelling the relationship between carbon price and its determinants. However, the quantile regression model doesn't need any assumption of the distribution of residuals, and so can perform better.
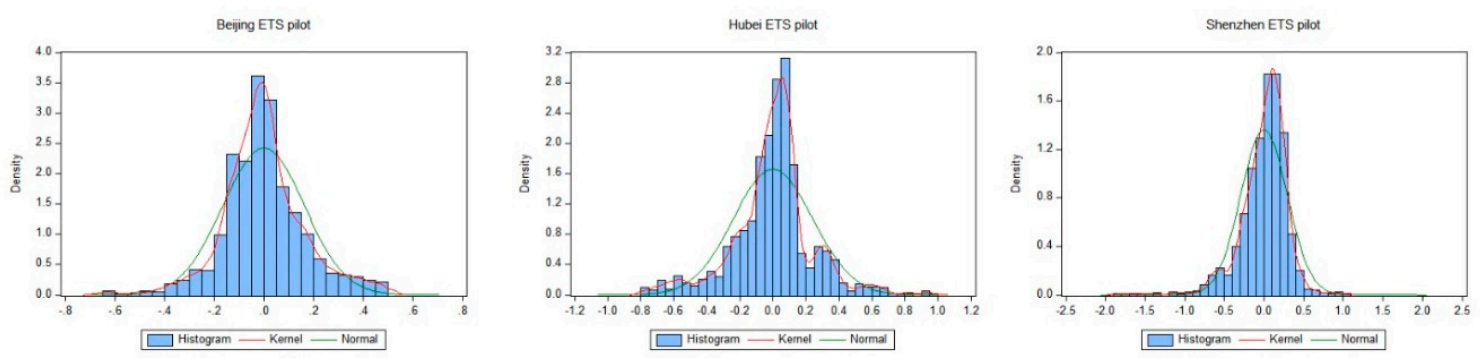

Figure 3. Normality test of the residuals of OLS in Beijing, Hubei and Shenzhen ETS pilots.

The results of Brock-Decher-Scheikman (BDS) test are shown in Table 2. The results indicate that the relationship between carbon price and its determinants are nonlinear at the significance level of $1 \%$. Therefore, the semiparametric quantile regression technique was provided to model the relationship between the carbon prices and its drivers in China's pilots, in order to overcome the deficiencies of OLS and achieve a better performance than that of other traditional methods. 
Table 2. BDS test results.

\begin{tabular}{|c|c|c|c|c|c|c|c|c|c|c|}
\hline \multirow{3}{*}{ Pilots } & \multirow{3}{*}{$\begin{array}{c}\text { Carbon } \\
\text { Price/Determinants }\end{array}$} & \multicolumn{8}{|c|}{ m-Dimensional Space } & \multirow{3}{*}{ Linearity } \\
\hline & & \multicolumn{2}{|c|}{2} & \multicolumn{2}{|c|}{3} & \multicolumn{2}{|c|}{4} & \multicolumn{2}{|c|}{5} & \\
\hline & & Stat. & Prob. & Stat. & Prob. & Stat. & Prob. & Stat. & Prob. & \\
\hline \multirow[t]{4}{*}{ Beijing } & BJA/COAL & 0.1387 & 0.0000 & 0.2319 & 0.0000 & 0.2908 & 0.0000 & 0.3258 & 0.0000 & $\mathrm{NO}$ \\
\hline & BJA/OIL & 0.1459 & 0.0000 & 0.2437 & 0.0000 & 0.3055 & 0.0000 & 0.3439 & 0.0000 & $\mathrm{NO}$ \\
\hline & BJA/LNG & 0.1406 & 0.0000 & 0.2360 & 0.0000 & 0.2980 & 0.0000 & 0.3369 & 0.0000 & $\mathrm{NO}$ \\
\hline & BJA/STOCK & 0.1497 & 0.0000 & 0.2535 & 0.0000 & 0.3211 & 0.0000 & 0.3638 & 0.0000 & $\mathrm{NO}$ \\
\hline \multirow[t]{4}{*}{ Hubei } & HBA/COAL & 0.1934 & 0.0000 & 0.3296 & 0.0000 & 0.4237 & 0.0000 & 0.4883 & 0.0000 & $\mathrm{NO}$ \\
\hline & HBA/OIL & 0.1906 & 0.0000 & 0.3254 & 0.0000 & 0.4192 & 0.0000 & 0.4840 & 0.0000 & $\mathrm{NO}$ \\
\hline & HBA/LNG & 0.1878 & 0.0000 & 0.3194 & 0.0000 & 0.4101 & 0.0000 & 0.4721 & 0.0000 & $\mathrm{NO}$ \\
\hline & HBA/STOCK & 0.1914 & 0.0000 & 0.3263 & 0.0000 & 0.4199 & 0.0000 & 0.4843 & 0.0000 & $\mathrm{NO}$ \\
\hline \multirow[t]{4}{*}{ Shenzhen } & SZA/COAL & 0.1449 & 0.0000 & 0.2534 & 0.0000 & 0.3254 & 0.0000 & 0.3723 & 0.0000 & $\mathrm{NO}$ \\
\hline & SZA/OIL & 0.1330 & 0.0000 & 0.2339 & 0.0000 & 0.2999 & 0.0000 & 0.3424 & 0.0000 & $\mathrm{NO}$ \\
\hline & SZA/LNG & 0.1377 & 0.0000 & 0.2421 & 0.0000 & 0.3119 & 0.0000 & 0.3578 & 0.0000 & $\mathrm{NO}$ \\
\hline & SZA/STOCK & 0.1545 & 0.0000 & 0.2682 & 0.0000 & 0.3440 & 0.0000 & 0.3946 & 0.0000 & $\mathrm{NO}$ \\
\hline
\end{tabular}

Note: NO shows that the relationship between carbon price and the price of its determinants is nonlinear at the significance level of $1 \%$.

\subsection{The Effects of Energy Prices on Carbon Prices}

The effects of energy prices on carbon prices in Beijing, Hubei and Shenzhen ETS pilots can be reflected by the slope coefficients of parametric components. The estimated parameters of the semiparametric quantile model are shown in Table 3. This table shows that the effects of energy prices on carbon prices are mostly significant. The effects of energy prices on carbon prices in three ETS pilots are obviously different for different quantiles of carbon prices. The effects of energy prices are shown graphically in Figures 4-6.

As for Beijing ETS pilot, coal prices have a significant and positive effect on the carbon prices (see Table 3) in almost all quantiles, which is consistent with Tan and Wang [34], who showed that coal prices positively affected carbon prices in Phase II of the EU ETS. A possible explanation for these observations is that, because Beijing is at the forefront of economic development in China, a large amount of energy is needed for the high-speed development of the economy, and Beijing's energy consumption gives priority to coal, in which case enterprises may not reduce the demand for coal even if coal prices are high, leading to an increase in the carbon prices. The results also indicate that coal prices have a greater effect for higher quantile levels. The effects of changes to oil prices on carbon prices are not significant in low quantiles, but are significantly negative in high quantiles (see Figure 4).

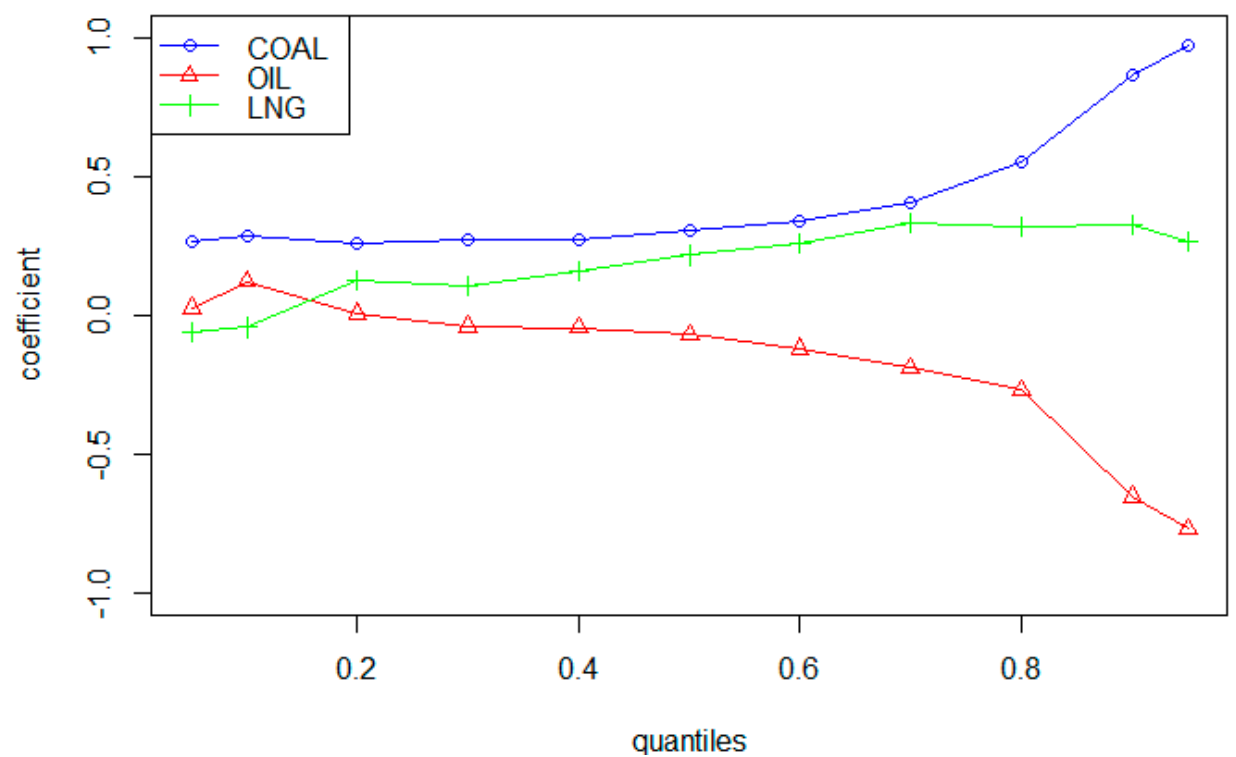

Figure 4. Effects of energy prices on carbon prices in the Beijing ETS pilot. 
Table 3. Semiparametric quantile regression results: slope coefficients for three ETS pilots.

\begin{tabular}{|c|c|c|c|c|c|c|c|c|c|c|c|c|}
\hline Pilots & Variable & $Q_{0.05}$ & $Q_{0.1}$ & $Q_{0.2}$ & $Q_{0.3}$ & $Q_{0.4}$ & $Q_{0.5}$ & $Q_{0.6}$ & $Q_{0.7}$ & $Q_{0.8}$ & $Q_{0.9}$ & $Q_{0.95}$ \\
\hline \multirow[t]{3}{*}{ Beijing } & $\beta_{\text {coal }}$ & $0.265^{* * *}$ & $0.284^{* * *}$ & $0.258^{* * *}$ & $0.272 * * *$ & $0.273^{* * *}$ & $0.304^{* * *}$ & $0.337^{* * *}$ & $0.404^{* * *}$ & $0.555^{* * *}$ & $0.865 * * *$ & $0.976^{* * *}$ \\
\hline & $\beta_{\mathrm{oil}}$ & 0.028 & $0.122 *$ & 0.008 & -0.041 & -0.045 & -0.069 & $-0.119 *$ & $-0.190^{* *}$ & $-0.269 * *$ & $-0.654^{* * *}$ & $-0.772^{* * *}$ \\
\hline & $\beta_{\mathrm{LNG}}$ & -0.061 & -0.044 & $0.126^{* * *}$ & $0.107^{* * *}$ & $0.161^{* * *}$ & $0.217^{* * *}$ & $0.261^{* * *}$ & $0.334^{* * *}$ & $0.320^{* * *}$ & $0.325^{* *}$ & $0.267^{*}$ \\
\hline \multirow[t]{3}{*}{ Hubei } & $\beta_{\text {coal }}$ & -0.133 & -0.068 & -0.153 & $-0.225 *$ & $-0.356^{* * *}$ & $-0.381^{* * *}$ & $-0.356^{* * *}$ & $-0.381^{* * *}$ & $-0.278^{* *}$ & 0.258 & $0.408^{* *}$ \\
\hline & $\beta_{\text {oil }}$ & -0.097 & $-0.207^{* *}$ & -0.153 * & $-0.251^{* * *}$ & $-0.298^{* * *}$ & $-0.280^{* * *}$ & $-0.324^{* * *}$ & $-0.228^{* * *}$ & $-0.151^{* *}$ & $-0.608^{* * *}$ & $-0.754^{* * *}$ \\
\hline & $\beta_{\mathrm{LNG}}$ & $0.211^{* * *}$ & $0.207^{* * *}$ & $0.213^{* * *}$ & $0.246^{* * *}$ & $0.300^{* * *}$ & $0.363^{* * *}$ & $0.509^{* * *}$ & $0.510^{* * *}$ & $0.536^{* * *}$ & $0.519^{* * *}$ & $0.505^{* * *}$ \\
\hline \multirow[t]{3}{*}{ Shenzhen } & $\beta_{\text {coal }}$ & $-2.095^{* * *}$ & $-1.572^{* * *}$ & $-1.376^{* * *}$ & $-1.334^{* * *}$ & $-1.207^{* * *}$ & $-1.174^{* * *}$ & $-1.122^{* * *}$ & $-1.104^{* * *}$ & $-0.981^{* * *}$ & $-0.952^{* * *}$ & $-0.902^{* * *}$ \\
\hline & $\beta_{\text {oil }}$ & $1.786^{* * *}$ & $1.207^{* * *}$ & $0.974^{* * *}$ & $0.935^{* * *}$ & $0.777^{* * *}$ & $0.776^{* * *}$ & $0.772 * * *$ & $0.808^{* * *}$ & $0.712 * * *$ & $0.766^{* * *}$ & $0.712^{* * *}$ \\
\hline & $\beta_{\mathrm{LNG}}$ & 0.323 & -0.118 & 0.071 & $0.196^{* * *}$ & $0.226^{* * *}$ & $0.228^{* * *}$ & 0.238 & $0.214^{* * *}$ & $0.182 * * *$ & $0.108^{* *}$ & 0.036 \\
\hline
\end{tabular}

Note: The table reports the results of the parametric coefficients of semiparametric quantile regression. ${ }^{* * *}$ Denotes the rejection of the null hypothesis at a significance level of $0.1 \%$.

${ }^{*}$ Denotes the rejection of the null hypothesis at a significance level of $1 \% .{ }^{*}$ Denotes the rejection of the null hypothesis at a significance level of $5 \%$. ^ Denotes the rejection of the null

hypothesis at a significance level of $10 \%$ 
Consistent with Hammoudeh et al. [19], a rise in crude oil prices leads to a decrease in carbon prices when carbon prices are very high. This result may be attributed to the lower carbon emitted and the lower carbon prices that result from a decrease in the oil consumption caused by higher oil prices. Due to the high production cost of using oil, enterprises will use less oil when carbon prices are high. Therefore, the negative impacts are greater at the right tail of the carbon price distribution. Natural gas prices have significantly positive impacts on carbon prices, which are consistent with the results of Tan and Wang [34], who showed that natural gas prices positively affected carbon prices in Phase II. However, the effects are negative but not significant when the carbon prices are extremely low (at 0.05 and 0.1 quantiles). Moreover, the positive effects of natural gas prices increase with the rise of quantiles (see Figure 4). The non-significant impacts can be attributed to the fact that the price of natural gas is not market-oriented [51]. The largest feature of the natural gas industry in China is its strong monopoly [63]. The positive impacts may indicate that the increase in the natural gas prices can induce enterprises to use more non-clean energy and generate more carbon emissions. Thus, the demand for carbon emission allowances increases, resulting in the increase of carbon prices.

The Hubei ETS pilot indicated that an increase in coal prices can generate a substantial drop in carbon prices, except for extremely high quantiles (at 0.9 and 0.95 quantiles). This negative relationship is consistent with Zhou and Li [13], who confirmed that coal prices had negative impacts on carbon prices in the Hubei ETS pilot. An energy-intensive industry occupies a large proportion of the industrial structure of Hubei Province, and coal is the main energy [49]. The higher coal prices could cause enterprises to use less coal to cut costs, and would consequently decrease the demand for carbon emission allowances, resulting in a decrease in carbon prices. Similarly to coal, the negative effect of rising oil prices on carbon prices has existed at all quantile levels. This has resulted in several studies $[24,34]$ that have analyzed the relationship between oil prices and carbon prices. As indicated, the increase in oil prices reduces its consumption, which in turn diminishes the need for carbon emission allowances, leading to lower carbon prices. In contrast, natural gas prices have significantly positive effects on carbon prices, as shown in Table 3 and Figure 5.

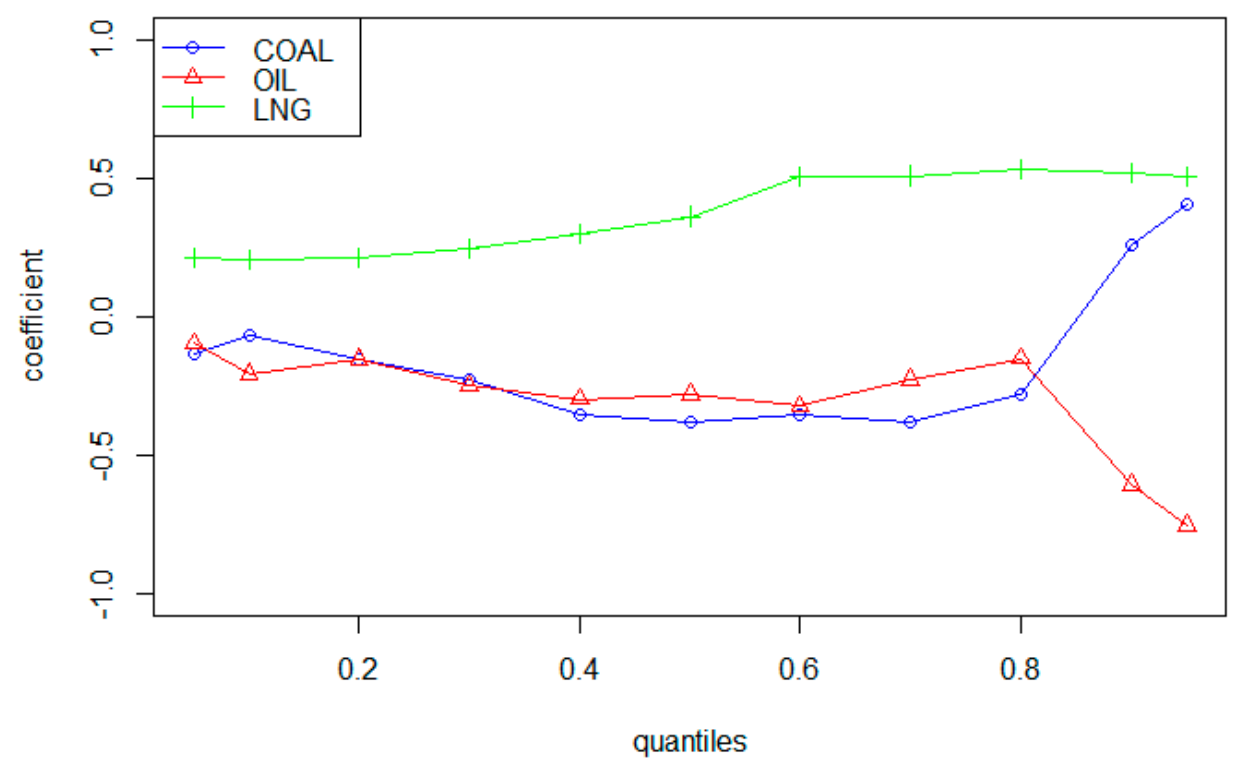

Figure 5. Effects of energy prices on carbon prices in the Hubei ETS pilot.

In addition, one of the more surprising findings is that the effect is variable at different quantiles. This suggests that natural gas prices play a greater role in carbon prices at higher quantiles (i.e., when the carbon price is higher), and vice versa. This may be due to rising natural gas prices, which have driven people to use more alternative non-clean energy, and thus release more $\mathrm{CO}_{2}$. As a result, carbon emission allowances have become tighter, which has led to higher carbon prices. In practice, 
enterprises use more non-clean energy because of energy-intensive industries in the Hubei ETS pilot, which have greater effects on carbon prices.

In the Shenzhen ETS pilot, we found a high level of carbon emissions in spite of the declining share of emission-intensive manufacturing sectors, which is consistent with the conclusion of Cong and Lo [12]. Figure 6 shows that coal prices had significant and negative effects on carbon prices in the Shenzhen ETS pilot. The results are consistent with those of Tan and Wang [34], who concluded that coal prices negatively influenced carbon prices in Phase I and Phase III of the EU ETS. As shown in Table 3, the negative influence of the coal price on the carbon price is significant at each quantile level, and the influence is greater at the lower quantile level, whereas it is lower at the higher quantile level. This may be because the rising carbon prices (i.e., at the higher quantile level) lead enterprises to cut production and use less coal. Therefore, the impact of coal prices on carbon prices diminishes as the quantile increases. Oil prices have a significant and positive effect on carbon prices. This is consistent with the results of Hammoudeh et al. [18], who conclude that a human-induced shock to oil prices can initially result in the rise of carbon prices. More interesting is that the characteristics of the dependence change between oil prices and carbon prices from low quantiles to high quantiles (see Table 3 and Figure 6). In contrast with the results of Tan and Wang [34], who showed incoherent changes (i.e., neither gradually declining nor continuously rising) without regularity, we find that the impact of oil prices on carbon prices declines as the quantile increases. Our novel finding may have been generated by the following conditions. The rising carbon prices with higher quantiles drive companies' production reduction plans, which can reduce oil consumption and therefore decrease the impact of oil prices on carbon prices. For the impact of natural gas prices, it is similar to the two other pilot projects in Beijing and Hubei, which both have significant and positive effects on carbon prices.

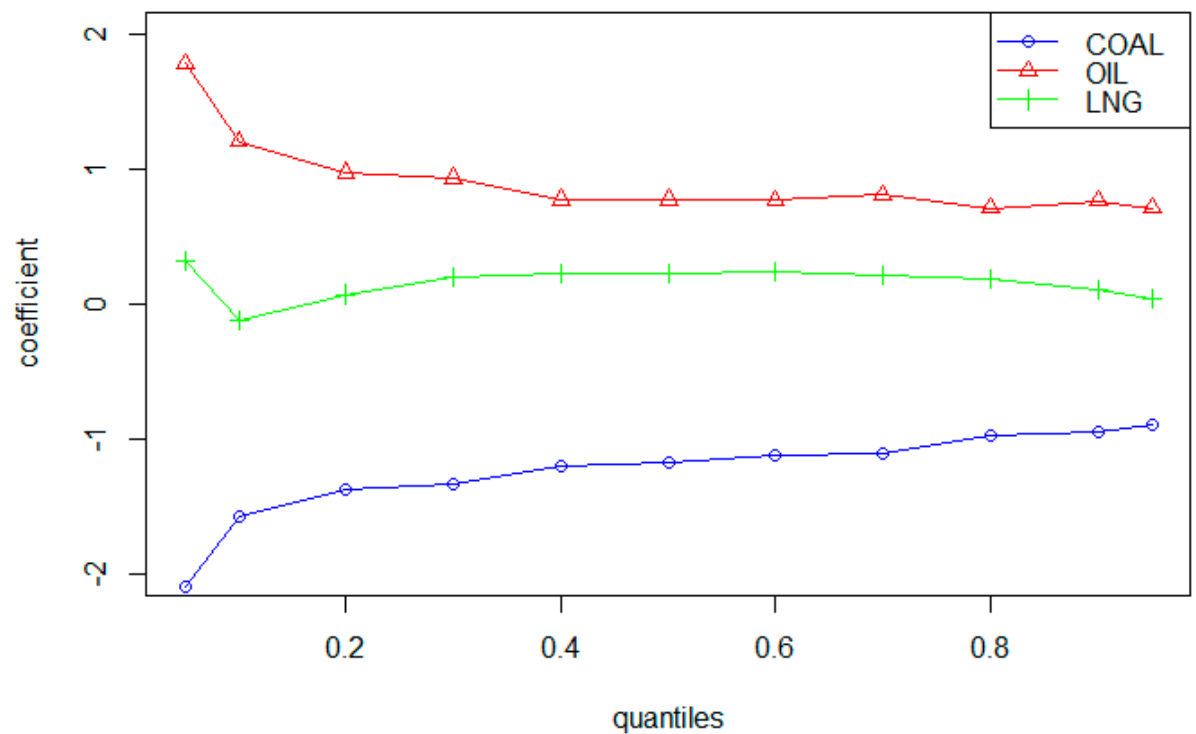

Figure 6. Effects of energy prices on carbon prices in the Shenzhen ETS pilot.

\subsection{The Effects of the Macroeconomic Level on Carbon Prices}

The effects of the macroeconomic level on carbon prices in the ETS pilots of Beijing, Hubei and Shenzhen were examined as nonparametric components of our proposed semiparametric quantile regression model. To further illustrate the impact of macroeconomic factors at different carbon price levels, we took results from the $0.2,0.5$ and 0.8 quantiles to graphically indicate carbon prices at low, medium and high levels, respectively. The estimates of this model for all quantiles are presented in Table 4, including the smoothing parameters, the F statistics and their associated probabilities. The null hypothesis of the F-test is $m_{d}=0$ for $d=1 \ldots D$. The F-statistics are provided as part of the output from the $\mathbf{R}$ functions in Koenker [55]. Table 4 shows that the results reject the null hypothesis at a significance level of $0.1 \%$, which indicates that macroeconomic factors had significant impacts on 
carbon prices in the Beijing, Hubei and Shenzhen ETS pilots of China. Several detailed empirical results are as follows.

Figures 7-9 show the effects of the macroeconomic level on carbon prices for the $20 \%, 50 \%$ and $80 \%$ quantiles in the three ETS pilots. In the Beijing ETS pilot, the effect of the macroeconomic level on carbon prices is positive, which is consistent with Chevallier [27]. We can see from a graphical representation in Figure 7 that the effects of STOCK on carbon prices are positive. Due to the lower emission threshold and area covered in the Beijing ETS pilot [64], the macroeconomic level that influences the development of industrial corporations is less likely to cause fluctuations in carbon prices. However, this effect is not constant, but is liable to decrease from the lower to higher quantiles, and conversely, carbon prices tend to be heavily influenced by macroeconomic fluctuations if the carbon prices are not very high. Thus, we suggest that high prices of carbon allowances are not conducive to the impacts of economic factors on carbon price, which may be advisable for policymakers for carbon pricing.
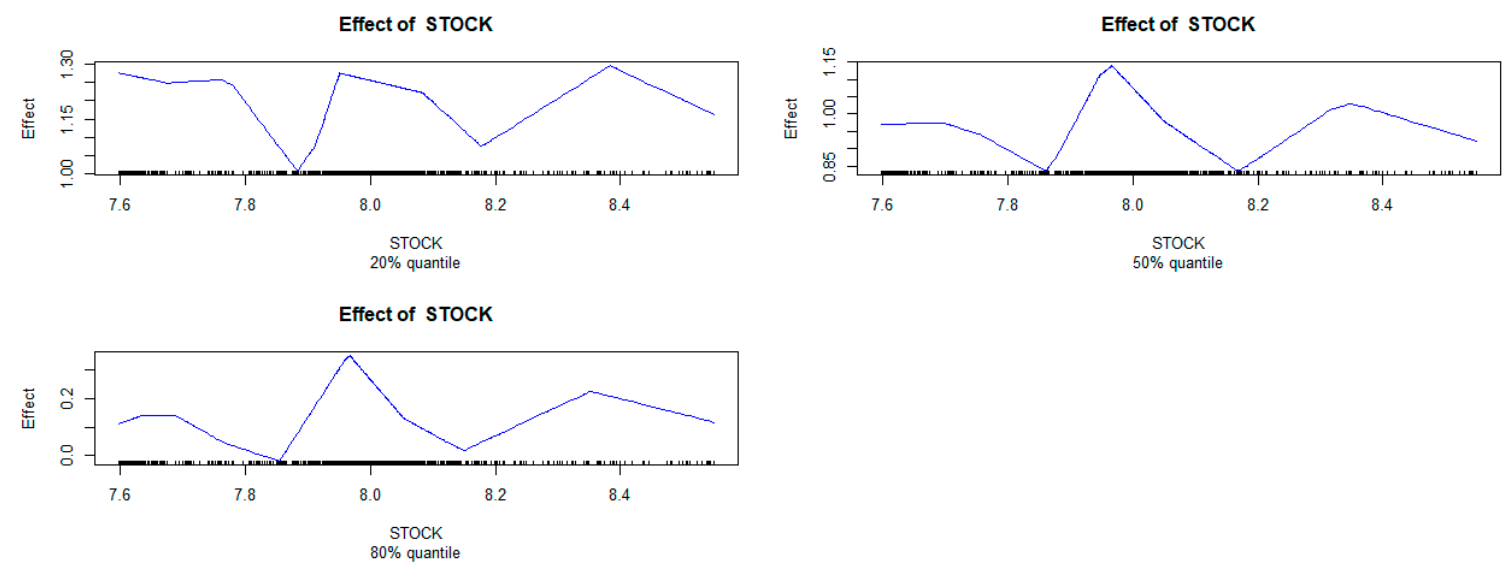

Figure 7. Effects of STOCK on carbon prices in the Beijing ETS pilot.

Similarly to the Beijing ETS pilot, the effects of the macroeconomic level on carbon prices are obviously positive in the Hubei ETS pilot, as shown in Figure 8. The positive impact can be attributed to a booming economy associated with a higher output and more energy consumption, which always leads to higher carbon emissions and a higher carbon price. However, the effects of the macroeconomic level on carbon prices are not constant from the low quantiles to the high quantiles; the effects of the macroeconomic level on carbon prices at the low and high quantiles are smaller than those at the medium quantile, which indicates that the medium carbon prices are more likely to fluctuate due to the changes in the macroeconomic level. This suggests that medium priced carbon allowances are more sensitive to changes in macroeconomic factors.
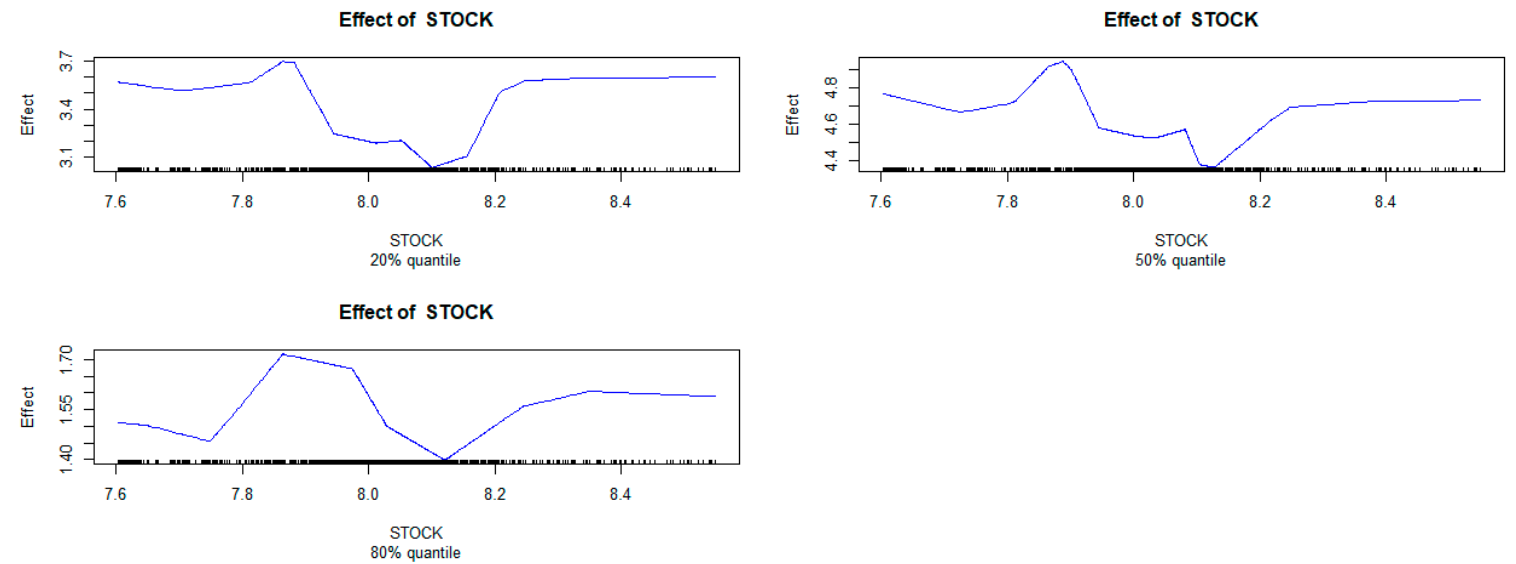

Figure 8. Effects of STOCK on carbon prices in the Hubei ETS pilot. 
Table 4. Estimation and test of the non-parametric term in a semi-parametric quantile regression.

\begin{tabular}{|c|c|c|c|c|c|c|c|c|c|c|c|c|}
\hline Pilot & & $\mathrm{Q}_{0.05}$ & $\mathrm{Q}_{0.1}$ & $\mathrm{Q}_{0.2}$ & $\mathrm{Q}_{0.3}$ & $\mathrm{Q}_{0.4}$ & $\mathrm{Q}_{0.5}$ & $\mathrm{Q}_{0.6}$ & $\mathrm{Q}_{0.7}$ & $\mathrm{Q}_{0.8}$ & $\mathrm{Q}_{0.9}$ & $\mathrm{Q}_{0.95}$ \\
\hline \multirow[t]{4}{*}{ Beijing } & Lambda & 0.089 & 0.286 & 0.081 & 0.119 & 0.141 & 0.161 & 0.268 & 0.098 & 0.173 & 0.064 & 0.064 \\
\hline & Penalty & 13.31 & 3.988 & 21.52 & 15.42 & 16.2 & 16.86 & 13.01 & 19.52 & 17.07 & 30.62 & 29.65 \\
\hline & F statistics & 7.576 & 4.005 & 8.119 & 1.66 & 10.18 & 5.921 & 10.42 & 21.75 & 6.304 & 31.25 & 46.02 \\
\hline & $\mathrm{P}(>\mathrm{F})$ & $0.000 * * *$ & $0.000^{* * *}$ & $0.000^{* * *}$ & $0.003^{* *}$ & $0.000^{* * *}$ & $0.000^{* * *}$ & $0.000^{* * *}$ & $0.000^{* * *}$ & $0.000^{* * *}$ & $0.000^{* * *}$ & $0.000^{* * *}$ \\
\hline \multirow[t]{4}{*}{ Hubei } & Lambda & 0.017 & 0.032 & 0.108 & 0.198 & 0.103 & 0.124 & 0.340 & 0.131 & 0.151 & 0.107 & 0.052 \\
\hline & Penalty & 138.8 & 85.1 & 43.34 & 31.01 & 41.95 & 47.47 & 25.25 & 26.93 & 20.72 & 31.84 & 42.45 \\
\hline & F statistics & 56.28 & 85.08 & 15.47 & 57.82 & 64.3 & 39.66 & 31.93 & 2.803 & 4.704 & 25.45 & 42.44 \\
\hline & $\mathrm{P}(>\mathrm{F})$ & $0.000^{* * *}$ & $0.000^{* * *}$ & $0.000^{* * *}$ & $0.000^{* * *}$ & $0.000^{* * *}$ & $0.000^{* * *}$ & $0.000^{* * *}$ & $0.000^{* * *}$ & $0.000^{* * *}$ & $0.000^{* * *}$ & $0.000^{* * *}$ \\
\hline \multirow[t]{4}{*}{ Shenzhen } & Lambda & 0.026 & 0.081 & 0.196 & 0.24 & 0.176 & 0.189 & 0.141 & 0.196 & 0.058 & 0.121 & 0.109 \\
\hline & Penalty & 129.1 & 64.14 & 30.24 & 31.27 & 41.57 & 35.74 & 33.63 & 23.02 & 60.51 & 14.21 & 12.55 \\
\hline & F statistics & 64.08 & 79.68 & 68.26 & $1.458 \times 10^{9}$ & 94.39 & 3.724 & 79.08 & 65.43 & 17.14 & 38.94 & 29.21 \\
\hline & $\mathrm{P}(>\mathrm{F})$ & $0.000^{* * *}$ & $0.000^{* * *}$ & $0.000^{* * *}$ & $0.000^{* * *}$ & $0.000^{* * *}$ & $0.000 * * *$ & $0.000^{* * *}$ & $0.000 * * *$ & $0.000^{* * *}$ & $0.000^{* * *}$ & $0.000^{* * *}$ \\
\hline
\end{tabular}

Note: The table reports the results of a nonparametric item of semiparametric quantile regression. ${ }^{* * *}$ Denotes the rejection of the null hypothesis at a significance level of $0.1 \%$. ${ }^{* *}$ Denotes the rejection of the null hypothesis at a significance level of $1 \%$. * Denotes the rejection of the null hypothesis at a significance level of $5 \%$. ^ Denotes the rejection of the null hypothesis at a significance level of $10 \%$. 
Consistent with the former findings, the Shenzhen pilot also showed a significant positive relationship between the macroeconomic level and the carbon price, which was also concluded by Guo [65]. Figure 9 indicates that the curves describing the effects of the macroeconomic factors on carbon prices for the 0.2, 0.5 and 0.8 quantiles are approximately V-shaped, with little difference. This shape suggests that the effects on the carbon price is extremely high when the macroeconomic level is lower, but this effect gradually decreases to the bottom of the V-shaped curve. In addition, this effect becomes larger as the macroeconomic level increases, and it gradually becomes stationary after reaching a certain level.

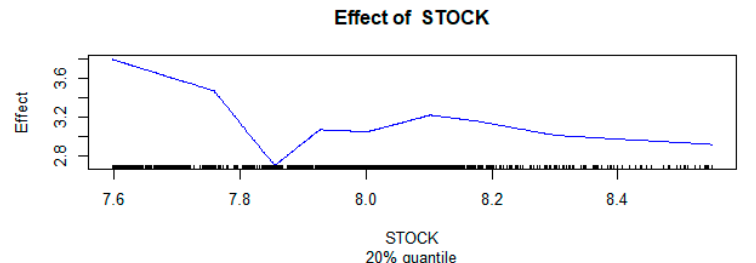

STOCK
$20 \%$ quantile

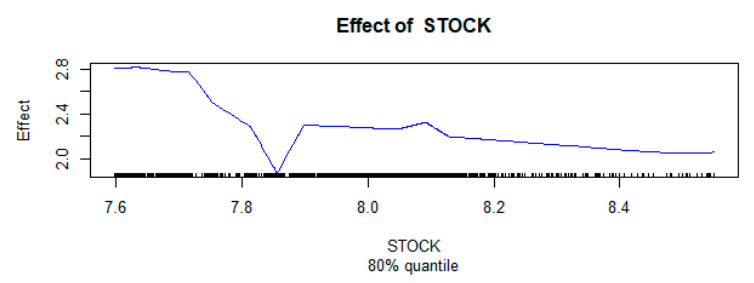

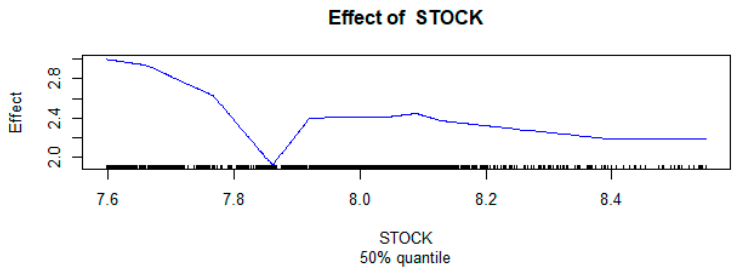

STOCK
$50 \%$ quantile

Figure 9. Effects of STOCK on carbon prices in the Shenzhen ETS pilot.

\section{Conclusions and Implications}

In this paper, we employed a semiparametric quantile regression to investigate the nonlinear effects of energy prices and the macroeconomic level on carbon prices in three ETS pilots: the Beijing, Hubei and Shenzhen ETS pilots. The effects of determinants on carbon prices are obviously different at different quantiles of carbon prices. For the Beijing ETS pilots, investors and enterprises can predict the higher carbon prices by the increased coal prices. For the Hubei and Shenzhen ETS pilots, the increase of coal prices hints the decrease of carbon prices. Especially, the fluctuation of coal prices in the Shenzhen ETS pilot lead to more violent fluctuations of carbon prices at lower carbon prices. Additionally, the effects of coal prices were larger than those of oil prices and natural gas prices in the Beijing and Shenzhen ETS pilots, which indicates that the coal prices are the main driving factors. Therefore, the government can increase coal prices to indirectly improve carbon prices in the Beijing ETS pilot to reduce the demand for carbon allowance, which can effectively reduce carbon emissions.

From the empirical results, we can conclude that natural gas price can positively influence carbon prices, which can be attributed to the fact that enterprises will reduce the use of natural gas when natural gas prices are high. In China, the price of natural gas has been under a strong monopoly in recent decades, and coal is still the main energy source for China. Therefore, industrial upgrading and energy restructuring should be accelerated to reduce the demand for coal and increase the proportion of clean and renewable energy. A modest cut in the price of natural gas by the government might cause enterprises to use more of it, which can reduce the carbon emissions. Furthermore, the use of more natural gas can lead to lower carbon prices; thus, investors should focus on reforming energy pricing to make investment decisions. For example, inventors can predict lower carbon prices by the decrease of natural gas prices.

The response of carbon prices to the macroeconomic level is violent, which can cause fluctuations in carbon prices. However, large fluctuations may lead to an increase in the transaction costs of enterprises, which can restrain enterprises from participating in the carbon market. Therefore, policymakers should pay close attention to the fluctuations of carbon prices, and several policies should be put into place to improve market supervisions to adjust carbon prices in a timely and effective manner, in order to 
reduce market risks. In addition, it is advisable for investors to forecast the fluctuations in carbon prices based on the macroeconomic level. If the investors or enterprises predict improving economic situations, it may be advantageous for inventors and enterprises to buy more carbon allowances in advance. For the Beijing and Shenzhen ETS pilots, improving the macroeconomic level had greater impacts on carbon prices in low quantiles, which indicates that buying Beijing or Shenzhen carbon allowances in low carbon prices is more favorable for inventors and enterprises when the economic level is improving.

The results of the paper indicate that carbon prices are susceptible to external factors, such as energy prices and the macroeconomic level, which results in relatively large fluctuations in carbon prices. It is essential to correct the failure of the carbon market through reasonable interventions from governments. The results show that energy prices can have an obvious effect on carbon prices; thus, the government can regulate energy prices and bring the carbon price back to a normal level. For example, if the carbon price is too high, a government can cause it to fall by lowering natural gas prices through market and administrative means. In addition, compared to scenarios within a mature international carbon market, China's ETS pilots still have problems, such as the simplicity of carbon financial products and the low trading volume. Thus, a relevant department should promote the innovation of carbon financial products and selectively introduce carbon financial products according to their characteristics. It is essential to develop carbon financial derivatives, such as carbon forwards, carbon futures and carbon options, to attract more market participants and promote the further development of the carbon market.

As previously mentioned, this paper provides recommendations for investors and policy-makers regarding strategic decisions. Investors should not only focus on the fluctuations of carbon prices but also focus on the changes in energy prices and the macroeconomic level. Policymakers should develop several regulations to ensure normal fluctuations in carbon prices and to moderate carbon prices. In addition, the government should promote the innovation of carbon financial products to ensure the normal operation of the carbon market. However, there are still limitations in our research. The period we studied doesn't cover periods of major disaster, such as COVID-19, which may cause different results. Therefore, this will be our topic of further investigation. In addition, there will be other determinants of carbon prices which we don't include in our research, such as the weather and electricity prices. The absence of determinants may result in the deviation of the results. For our next study, we should take account into these determinants.

Author Contributions: Conceptualization, S.C.; methodology, W.C. and S.C.; software, W.C.; validation, W.C. and X.C.; formal analysis, M.D.; investigation, W.C.; resources, S.C. and W.C.; data curation, W.C.; writing-original draft preparation, W.C. and S.C.; writing-review and editing, S.C. and X.C.; visualization, W.C.; supervision, X.C. and M.D.; project administration, S.C. and M.D.; funding acquisition, S.C. All authors have read and agreed to the published version of the manuscript.

Funding: This research was funded by [National Natural Science Foundation of China] grant number [71704098, 71974154, 71701115] and [Natural Science Foundation of Shandong Province] grant number [ZR2016GQ03, ZR2017QG003, ZR2017MF058]. The APC was funded by [National Natural Science Foundation of China] grant number [71704098].

Acknowledgments: The authors would like to express their sincere gratitude to the anonymous reviewers, and the editors for their truly valuable comments. This study appreciates the support from National Natural Science Foundation of China (NSFC, No. 71704098).

Conflicts of Interest: The authors declare that they have no conflict of interest.

\section{References}

1. Dudley, B. BP Statistical Review of World Energy; BP plc: London, UK, 2019.

2. UN (United Nations). Global Conference on Strengthening Synergies between the Paris Agreement and the 2030 Agenda for Sustainable Development: Maximizing Co-Benefits by Linking Implementation across SDGs and Climate Action; United Nations: New York, NY, USA, 2019. 
3. UN (United Nations). Transforming Our World: The 2030 Agenda for Sustainable Development; United Nations: New York, NY, USA, 2016.

4. UNFCCC (United Nations Framework Convention on Climate Change). Paris Agreement; United Nations: New York, NY, USA, 2015.

5. NDRC (National Development and Reform Commission). Enhanced Actions on Climate Change: China's Intended Nationally Determined Contributions; Department of Climate Change: Beijing, China, 2015.

6. Jiang, J.J.; Ye, B.; Ma, X.M. The construction of Shenzhen's carbon emission trading scheme. Energy Policy 2014, 75, 17-21. [CrossRef]

7. Zhang, Y.J.; Peng, Y.L.; Ma, C.Q.; Shen, B. Can environmental innovation facilitate carbon emissions reduction? Evidence from China. Energy Policy 2017, 100, 18-28. [CrossRef]

8. Chai, S.; Zhou, P. The Minimum-CVaR strategy with semi-parametric estimation in carbon market hedging problems. Energy Econ. 2018, 76, 64-75. [CrossRef]

9. ICAP (International Carbon Action Partnership). Emissions Trading Worldwide: Status Report 2018; ICAP: Berlin, Germany, 2018.

10. Jiang, J.; Xie, D.; Ye, B.; Shen, B.; Chen, Z. Research on China's cap-and-trade carbon emission trading scheme: Overview and outlook. Appl. Energy 2016, 178, 902-917. [CrossRef]

11. Munnings, C.; Morgenstern, R.D.; Wang, Z.; Liu, X. Assessing the design of three carbon trading pilot programs in China. Energy Policy 2016, 96, 688-699. [CrossRef]

12. Cong, R.; Lo, A.Y. Emission trading and carbon market performance in Shenzhen, China. Appl. Energy 2017, 193, 414-425. [CrossRef]

13. Zhou, K.; Li, Y. Influencing factors and fluctuation characteristics of China's carbon emission trading price. Phys. A Stat. Mech. Appl. 2019, 524, 459-474. [CrossRef]

14. Mansanet-Bataller, M.; Pardo, A.; Valor, E. CO2 prices, energy and weather. Energy J. 2007, 28, 67-86. [CrossRef]

15. Kim, H.S.; Koo, W.W. Factors affecting the carbon allowance market in the US. Energy Policy 2010, 38, 1879-1884. [CrossRef]

16. Creti, A.; Jouvet, P.A.; Mignon, V. Carbon price drivers: Phase I versus Phase II equilibrium? Energy Econ. 2012, 34, 327-334. [CrossRef]

17. Aatola, P.; Ollikainen, M.; Toppinen, A. Price determination in the EU ETS market: Theory and econometric analysis with market fundamentals. Energy Econ. 2013, 36, 380-395. [CrossRef]

18. Hammoudeh, S.; Nguyen, D.K.; Sousa, R.M. What explain the short-term dynamics of the prices of CO2 emissions? Energy Econ. 2014, 46, 122-135. [CrossRef]

19. Hammoudeh, S.; Nguyen, D.K.; Sousa, R.M. Energy prices and CO2 emission allowance prices: A quantile regression approach. Energy Policy 2014, 70, 201-206. [CrossRef]

20. Hammoudeh, S.; Lahiani, A.; Nguyen, D.K.; Sousa, R.M. An empirical analysis of energy cost pass-through to CO2 emission prices. Energy Econ. 2015, 49, 149-156. [CrossRef]

21. Yu, L.; Li, J.; Tang, L.; Wang, S. Linear and nonlinear Granger causality investigation between carbon market and crude oil market: A multi-scale approach. Energy Econ. 2015, 51, 300-311. [CrossRef]

22. Zhang, Y.J.; Sun, Y.F. The dynamic volatility spillover between European carbon trading market and fossil energy market. J. Clean. Prod. 2016, 112, 2654-2663. [CrossRef]

23. Chung, C.; Jeong, M.; Young, J. The Price Determinants of the EU Allowance in the EU Emissions Trading Scheme. Sustainability 2018, 10, 4009. [CrossRef]

24. Zhu, B.; Ye, S.; Han, D.; Wang, P.; He, K.; Wei, Y.M.; Xie, R. A multiscale analysis for carbon price drivers. Energy Econ. 2019, 78, 202-216. [CrossRef]

25. Chevallier, J.; Nguyen, D.K.; Reboredo, J.C. A conditional dependence approach to CO2-energy price relationships. Energy Econ. 2019, 81, 812-821. [CrossRef]

26. Liu, X.; Jin, Z. An analysis of the interactions between electricity, fossil fuel and carbon market prices in Guangdong, China. Energy Sustain. Dev. 2020, 55, 82-94. [CrossRef]

27. Chevallier, J. Evaluating the carbon-macroeconomy relationship: Evidence from threshold vector error-correction and Markov-switching VAR models. Econ. Model. 2011, 28, 2634-2656. [CrossRef]

28. Lutz, B.J.; Pigorsch, U.; Rotfuß, W. Nonlinearity in cap-and-trade systems: The EUA price and its fundamentals. Energy Econ. 2013, 40, 222-232. [CrossRef] 
29. Koch, N.; Fuss, S.; Grosjean, G.; Edenhofer, O. Causes of the EU ETS price drop: Recession, CDM, renewable policies or a bit of everything?-New evidence. Energy Policy 2014, 73, 676-685. [CrossRef]

30. Sousa, R.; Aguiar-Conraria, L.; Soares, M.J. Carbon financial markets: A time-frequency analysis of CO2 prices. Phys. A Stat. Mech. Appl. 2014, 414, 118-127. [CrossRef]

31. Jiménez-Rodríguez, R. What happens to the relationship between EU allowances prices and stock market indices in Europe? Energy Econ. 2019, 81, 13-24. [CrossRef]

32. Yuan, N.; Yang, L. Asymmetric risk spillover between financial market uncertainty and the carbon market: A GAS-DCS-copula approach. J. Clean. Prod. 2020, 259, 120750. [CrossRef]

33. Bredin, D.; Muckley, C. An emerging equilibrium in the EU emissions trading scheme. Energy Econ. 2011, 33, 353-362. [CrossRef]

34. Tan, X.P.; Wang, X.Y. Dependence changes between the carbon price and its fundamentals: A quantile regression approach. Appl. Energy 2017, 190, 306-325. [CrossRef]

35. Cai, Z.; Chen, L.; Fang, Y. A semiparametric quantile panel data model with an application to estimating the growth effect of FDI. J. Econom. 2018, 206, 531-553. [CrossRef]

36. Azomahou, T.; Laisney, F.; Van, P.N. Economic development and CO2 emissions: A nonparametric panel approach. J. Public Econ. 2006, 90, 1347-1363. [CrossRef]

37. Shahbaz, M.; Shafiullah, M.; Papavassiliou, V.G.; Hammoudeh, S.M. The CO2-growth nexus revisited: A nonparametric analysis for the G7 economies over nearly two centuries. Energy Econ. 2017, 65, 183-193. [CrossRef]

38. Cai, Z.; Xiao, Z. Semiparametric quantile regression estimation in dynamic models with partially varying coefficients. J. Econom. 2012, 167, 413-425. [CrossRef]

39. Koenker, R.; Bassett, G., Jr. Regression quantiles. Econom. J. Econom. Soc. 1978, 46, 33-50. [CrossRef]

40. Fan, Y.; Liu, R. A direct approach to inference in nonparametric and semiparametric quantile models. J. Econom. 2016, 191, 196-216. [CrossRef]

41. Chuang, C.C.; Kuan, C.M.; Lin, H.Y. Causality in quantiles and dynamic stock return-volume relations. J. Clean. Prod. 2009, 33, 1351-1360. [CrossRef]

42. Lee, B.S.; Li, M.Y.L. Diversification and risk-adjusted performance: A quantile regression approach. J. Bank. Financ. 2012, 36, 2157-2173. [CrossRef]

43. Zhu, H.; Guo, Y.; You, W.; Xu, Y. The heterogeneity dependence between crude oil price changes and industry stock market returns in China: Evidence from a quantile regression approach. Energy Econ. 2016, 55, 30-41. [CrossRef]

44. Jiang, H.; Zhang, J.; Sun, C. How does capital buffer affect bank risk-taking? New evidence from China using quantile regression. China Econ. Rev. 2019, 60, 101300. [CrossRef]

45. Lo, A.Y. Challenges to the development of carbon markets in China. Clim. Policy 2016, 16, 109-124. [CrossRef]

46. Weng, Q.; Xu, H. A review of China's carbon trading market. Renew. Sustain. Energy Rev. 2018, 91, 613-619. [CrossRef]

47. Chang, K.; Chen, R.; Chevallier, J. Market fragmentation, liquidity measures and improvement perspectives from China's emissions trading scheme pilots. Energy Econ. 2018, 75, 249-260. [CrossRef]

48. Zhao, X.; Zou, Y.; Yin, J.; Fan, X. Cointegration relationship between carbon price and its factors: Evidence from structural breaks analysis. Energy Procedia 2017, 142, 2503-2510. [CrossRef]

49. Chang, K.; Ge, F.; Zhang, C. The dynamic linkage effect between energy and emissions allowances price for regional emissions trading scheme pilots in China. Renew. Sustain. Energy Rev 2018, 98, 415-425. [CrossRef]

50. Fan, X.; Li, X.; Yin, J. Dynamic relationship between carbon price and coal price: Perspective based on Detrended Cross-Correlation Analysis. Energy Procedia 2019, 158, 3470-3475. [CrossRef]

51. Zeng, S.; Nan, X.; Liu, C.; Chen, J. The response of the Beijing carbon emissions allowance price (BJC) to macroeconomic and energy price indices. Energy Policy 2017, 106, 111-121. [CrossRef]

52. Chevallier, J. Modelling risk premia in CO2 allowances spot and futures prices. Econ. Model. 2010, 27, 717-729. [CrossRef]

53. Feng, Z.H.; Wei, Y.M.; Wang, K. Estimating risk for the carbon market via extreme value theory: An empirical analysis of the EU ETS. Appl. Energy 2012, 99, 97-108. [CrossRef]

54. Ibrahim, B.M.; Kalaitzoglou, I.A. Why do carbon prices and price volatility change? J. Bank. Financ. 2016, 63, 76-94. [CrossRef] 
55. Koenker, R. Additive models for quantile regression: Model selection and confidence bandaids. Braz. J. Probab. Stat. 2011, 25, 239-262. [CrossRef]

56. Schwarz, G. Estimating the dimension of a model. Ann. Stat. 1978, 6, 461-464. [CrossRef]

57. Zhang, J.; Zhang, L. Impacts on $\mathrm{CO} 2$ emission allowance prices in China: A quantile regression analysis of the Shanghai Emission Trading Scheme. Sustainability 2016, 8, 1195. [CrossRef]

58. Zheng, S. Study on Subject Matters of China Carbon Market; China Economic Publishing House: Beijing, China, 2019.

59. Duan, M.; Wu, L.; Qi, S. China Carbon Market Development Report from Pilot to National; People's Publication House: Beijing, China, 2018.

60. ICAP (International Carbon Action Partnership). Emissions Trading Worldwide: Status Report 2019; ICAP: Berlin, Germany, 2019.

61. Chang, K.; Lu, S.; Song, X. The impacts of liquidity dynamics on emissions allowances price: Different evidence from China's emissions trading pilots. J. Clean. Prod. 2018, 183, 786-796. [CrossRef]

62. Sun, Y. Annual Report of China Carbon Emissions Trading Scheme; Social Sciences Academic Press: Beijing, China, 2017.

63. Li, H.; Lei, M. The influencing factors of China carbon price: A study based on carbon trading market in Hubei province. Earth Environ. Sci. 2018, 121, 052073. [CrossRef]

64. Tan, X.; Wang, X. The market performance of carbon trading in China: A theoretical framework of structure-conduct-performance. J. Clean. Prod. 2017, 159, 410-424. [CrossRef]

65. Guo, W. Factors Impacting on the Price of China's Regional Carbon Emissions Based on Adaptive Lasso Method. China Popul. Resour. Environ. 2015, 25, 305-310. (In Chinese)

(C) 2020 by the authors. Licensee MDPI, Basel, Switzerland. This article is an open access article distributed under the terms and conditions of the Creative Commons Attribution (CC BY) license (http://creativecommons.org/licenses/by/4.0/). 